\title{
Frequency of Refractory Hypertension in Turkish Patients and Evaluation of the Factors Affecting Refractory Hypertension
}

\author{
Mustafa Temizel ${ }^{1,}$, , Ugur Dilek Calap ${ }^{1}$, Murtaza Cit ${ }^{1}$, Mansur Azermir ${ }^{1}$, Yucel Arman ${ }^{2}$ \\ ${ }^{1}$ Medicana International Hospital, Department of Internal Medicine, School of Medicine, Biruni University, Istanbul, Turkey \\ ${ }^{2}$ Department of Internal Medicine, Okmeydani Training and Research Hospital, Istanbul, Turkey

\section{Email address:} \\ mustafatemi@yahoo.com.tr (M. Temizel), dilekrahmanoglu@gmail.com (U. D. Calap), murtaza.cit@gmail.com (M. Cit), \\ drazarmir@hotmail.com (M. Azermir),dryarman@yahoo.com (Y. Arman) \\ ${ }^{*}$ Corresponding author
}

\section{To cite this article:}

Mustafa Temizel, Ugur Dilek Calap, Murtaza Cit, Mansur Azermir, Yucel Arman. Frequency of Refractory Hypertension in Turkish Patients and Evaluation of the Factors Affecting Refractory Hypertension. American Journal of Internal Medicine. Vol. 9, No. 1, 2021, pp. $21-25$. doi: 10.11648/j.ajim.20210901.14

Received: December 15, 2020; Accepted: January 15, 2021; Published: January 22, 2021

\begin{abstract}
Background: This study aimed to determine the frequency of refractory hypertension (RH) and investigate the factors affecting RH in Turkish hypertensive patients. Materials and methods: Totally 400 hypertensive patients (114 males and 286 females) were enrolled. Blood pressure (BP) was measured by patients at home two times a day. The patients were called for controlling in every four weeks, and those who had BP $<140 / 90 \mathrm{mmHg}$ were not followed-up. In patients with BP $>140 / 90 \mathrm{mmHg}$ drug doses were increased or another antihypertensive drug was added and the patients were continued to be followed-up. The total follow-up period was 36 weeks. Patients with persisting BP >140/90 mmHg despite triple medication administration including a diuretic form at least for 3 months at adequate doses were considered to have RH. Results: A total of 63 patients $(15.8 \%)$, including 14 males and 49 females, were considered to have RH. Body Mass Index (BMI) values of patients with and without $\mathrm{RH}$ were $32.16 \pm 3.56$ and $29.71 \pm 3.42$, respectively $(\mathrm{t}=2.92 ; \mathrm{p}=0.005)$. The rate of obese and morbidly obese patients was higher in the RH group $(\mathrm{p}<0.005)$. Duration of hypertension was longer in the $\mathrm{RH}$ group $(9.7 \pm 5.6 \mathrm{vs}$ $7.0 \pm 5.7$ years, $\mathrm{p}<0.001)$. Conclusion: We found the frequency of RH as $15.8 \%$. There's a significant correlation between BMI and RH. Duration of hypertension increases the prevalence of $\mathrm{RH}$, and should be considered one of the risks for $\mathrm{RH}$.
\end{abstract}

Keywords: Hypertension, Antihypertensive Agents, Blood Pressure

\section{Introduction}

Hypertension is one of the foremost causes of morbidity and mortality, affecting almost every organ systems in the body. It is suggested that approximately one billion people are affected by hypertension worldwide [1]. The estimated prevalence of hypertension is $29.3 \%$ in the general population [2] and $66.3 \%$ in the elderly [3]. In patients with hypertension, an increased risk for cardiovascular, cerebrovascular, and renal events have been reported $[4,5]$. The Framingham Heart Study defined that with an increase in severity of hypertension, the risk of major cardiovascular events increases in all age groups [6]. Moreover, Lewington et al determined that mortality due to ischemic heart disease and stroke increases gradually with a systolic BP (SBP) of higher than $115 \mathrm{mmHg}$ and a diastolic BP (DBP) of higher than $75 \mathrm{mmHg}$ [7].

Practice guidelines for the management of hypertension recommend a BP goal of $<140 / 90 \mathrm{mmHg}$ [8, 9]. More stringent measures are recommended for patients with diabetes $[8,10]$ and proteinuric chronic renal failure $[8,11]$.

Hypertension is difficult to control despite the use of combinations of antihypertensive drugs in some patients and is considered resistant hypertension.

Hypertension is generally defined as resistant or refractory to treatment if systolic and diastolic BP goal levels could not be reached, despite a therapeutic plan including lifestyle measures and the prescription of at least three medications 
(including a diuretic) at appropriate, excluding isolated office hypertension [8].

In this study, we aimed to examine the frequency of RH and to investigate the factors affecting $\mathrm{RH}$ in Turkish hypertensive patients.

\section{Materials and Methods}

In this study, 400 patients previously diagnosed with essential hypertension were enrolled.

The exclusion criteria included a history of any chronic cerebrovascular, cardiovascular, renal, hepatic, pancreatic or metabolic diseases, uncontrolled type 2 diabetes (glycosylated hemoglobin $>8.5 \%$ ) and patients over 80 years of age.

Medication usage was assessed during the screening visit. Drug classes included angiotensin-converting enzyme (ACE) inhibitors, angiotensin receptor blockers (ARB), betablockers, calcium channel blockers (dihydropyridine and nondihydropyridine), diuretics (thiazide and potassiumsparing), alpha-adrenergic receptor antagonists (Doxazosin), and central-acting drugs (Rilmenidin).

The patients were questioned for age, duration of hypertension, educational status, smoking habit, and diabetes status. Standardized anthropometric measurements (weight, height) were obtained on individuals in light clothing. BMI was calculated as body weight divided by height squared $\left(\mathrm{kg} / \mathrm{m}^{2}\right)$. Serum lipid levels (low density lipoprotein, high density lipoprotein, very low density lipoprotein and Triglyceride levels) were measured in all patients (Table 1).

All patients measured SBP and DBP using a digital sphygmomanometer at home. Patients were trained in the BP measurement method and tested. All BP measuring devices were checked for accuracy.

BP was measured by patients two times a day (in the morning, and the afternoon or evening). The patients were followed for 36 weeks.

The patients were called for controlling in every four weeks, and those who had BP $<140 / 90 \mathrm{mmHg}$ were not followed-up.

In patients with $\mathrm{BP}>140 / 90 \mathrm{mmHg}$ drug doses were increased or another antihypertensive drug was added and the patients were continued to be followed-up.

Patients with persisting BP $>140 / 90 \mathrm{mmHg}$ despite an administration of a triple medication including a diuretic form at least for 3 months at adequate doses were considered to have RH.

Patients were grouped according to the hypertension status and the results were compared between the patients with and without RH.

Statistical analyses were performed with SPSS version 16 software for Windows. The comparison between the patients with and without RH was made via the chi-square test and differences in the values of the variables between the groups were evaluated by the Mann Whitney-U test. The degree of the correlation between parameters was evaluated by regression analysis. A value of $\mathrm{p}<0.05$ was considered to be statistically significant.

\section{Results}

A total of 400 patients, 114 males $(28.5 \%)$ and 286 females $(71.5 \%)$, were evaluated in the study.

In the first follow-up (week four) $152(38 \%)$ participants, including 35 (31\%) men and 117 (41\%) women, had controlled hypertension and their follow-up did not continue.

During the study, 63 patients $(15.8 \%)$ were considered to have $\mathrm{RH}$, including 14 males and 49 females.

There were no significant differences between the groups regarding gender $(p=0.128)$, age $(p=0.809)$, educational status $(\mathrm{p}=0.465)$, diabetes $(\mathrm{p}=0.107)$, serum lipid levels $(\mathrm{p}=0.614)$ or smoking $(\mathrm{p}=0.959)$.

BMI values of patients with and without $\mathrm{RH}$ were detected as $32.16 \pm 3.56$ and $29.71 \pm 3.42$, respectively. The difference between groups was statistically significant $(\mathrm{t}=2.92$; $\mathrm{p}=0.005)$. The rate of obese and morbidly obese patients was higher in the RH group $(\mathrm{p}<0.005)$ (Table 1$)$.

Duration of hypertension was longer in the $\mathrm{RH}$ group: $9.7 \pm 5.6$ vs $7.0 \pm 5.7$ years $(p<0.001)$ (Table 1$)$.

In the regression analysis, coefficients of effective factors were analyzed; the effect capacity was 1.085 for BMI and 1.077 for the duration of hypertension (Table 2).

We could not find any cut-off value in ROC analysis of BMI and duration of hypertension to determine the RH.

Table 1. Baseline clinical characteristics of the study groups.

\begin{tabular}{|c|c|c|c|}
\hline Variables & RH group $(n=64)$ & Non-RH group $(n=337)$ & P value \\
\hline \multicolumn{4}{|l|}{ Gender (n, \%) } \\
\hline Male & $14(22.2)$ & $103(29.3)$ & \\
\hline Female & $49(77.8)$ & $234(70.7)$ & \\
\hline Total & $63(15.8)$ & $337(84.2)$ & 0.128 \\
\hline Age (years, mean \pm SD) & $57.8 \pm 9.6$ & $58.3 \pm 10.8$ & 0.809 \\
\hline \multicolumn{4}{|l|}{ Education level (n, \%) } \\
\hline Illiterate & $26(41.3)$ & $131(38.9)$ & \\
\hline Primary school & $30(47.6)$ & $151(44.8)$ & \\
\hline High school-Univers. & $1(1.6)$ & $19(5.6)$ & \\
\hline Total & 63 & 337 & 0.465 \\
\hline Duration of HT (years, mean \pm SD) & $9.7 \pm 5.6$ & $7.0 \pm 5.7$ & $<0.001$ \\
\hline Diabetes presence (n \%) & $20(31.7)$ & $75(22.3)$ & 0.107 \\
\hline Smoker status (n \%) & & & \\
\hline
\end{tabular}




\begin{tabular}{llll}
\hline Variables & RH group $(\mathbf{n}=\mathbf{6 4})$ & Non-RH group $(\mathbf{n}=\mathbf{3 3 7})$ & P value \\
\hline Smoker & $8(12.7)$ & $42(12.5)$ & \\
Nonsmoker & $55(87.3)$ & $295(87.5)$ & 0.959 \\
Total & 63 & 337 & 0.458 \\
Cholesterol $(\mathrm{mg} / \mathrm{dl})$ & 221 & 214 & 0.243 \\
LDL-c $(\mathrm{mg} / \mathrm{dl})$ & 167 & 149 & 0.719 \\
HDL-c $(\mathrm{mg} / \mathrm{dl})$ & 43 & 41 & 0.321 \\
VLDL-c $(\mathrm{mg} / \mathrm{dl})$ & 39 & 27 & 0.682 \\
Triglyceride $(\mathrm{mg} / \mathrm{dl})$ & 199 & 187 & 0.005 \\
BMI & $32.16 \pm 3.56$ & $29.71 \pm 3.42$ & \\
BMI distribution $(\mathrm{n} \%)$ & & & 0.005 \\
Normal weight & $6(9.5)$ & $53(15.7)$ & 0.005 \\
Overweight & $21(33.3)$ & $132(39.1)$ & $140(41.5)$ \\
$\quad$ Obese & $29(46.1)$ & $12(3.7)$ & \\
Morbidly obese & $7(11.1)$ & &
\end{tabular}

Table 2. Regression analysis.

\begin{tabular}{llllll}
\hline Parameter & B & Sig. & Wald & Exp (B) & 95\%CI for exp (B) \\
\hline BMI & 0.082 & 0.002 & 9.305 & 1.085 & $1.030-1.143$ \\
Duration of HT & 0.074 & 0.003 & 9.058 & 1.077 & $1.026-1.129$ \\
Constant & -4.448 & $<0.001$ & 26.817 & 0.012 & \\
\hline
\end{tabular}

CI, confidence interval; Exp (B), odds ratio; SE, standard error.

\section{Discussion}

The purpose of treatment in hypertensive patients is to reduce the long-term cardiovascular morbidity and mortality rates by controlling BP and other risk factors [8].

However, despite the known risks associated with hypertension and the variety of effective antihypertensive medications available, BP control remains suboptimal. In an analysis of NHANES participants under antihypertensive treatment, only $53 \%$ were having a $\mathrm{BP}<140 / 90 \mathrm{mmHg}$ [12]. In Framingham Heart Study, only $48 \%$ of treated participants were reported to have a $\mathrm{BP}<140 / 90 \mathrm{mmHg}$ and among elderly participants ( $>75$ years of age) less than $40 \%$ were having a goal BP [13]. In patients with diabetes mellitus or chronic kidney disease (CKD), the ratio of uncontrolled hypertension was higher. Of NHANES participants with CKD barely $37 \%$, and of participants with diabetes just $25 \%$ were reported to have a $\mathrm{BP}<130 / 85 \mathrm{mmHg}[12,14]$. In our study, only $152(38 \%)$ participants were at a goal BP in the first follow-up (week four), which shows an insufficient BP control close to high-risk groups.

The exact prevalence of RH is unknown. The estimated prevalence of $\mathrm{RH}$ in large trials for instances the ALLHAT, VALUE, ASCOTT, and CONVINCE trials, was 7-15\% [1518]. Previous studies suggested the prevalence of $\mathrm{RH}$ in tertiary care centers as 5-18\% [19-21], while a large cohort study by Alderman et al. reported the prevalence of $\mathrm{RH}$ as low as $2.9 \%$ [22]. Some clinical trials pointed out that RH was gradually more widespread. In the Systolic Hypertension in Europe (Syst-Eur) study, $43 \%$ of patients were determined to have RH [23], but isolated systolic hypertension in the elderly was frequently not incorporated in the assessments of prevalence of RH. In the LIFE (Losartan Intervention for Endpoint Reduction in Hypertension) study, which included hypertensive patients with left ventricular hypertrophy, $26 \%$ of the patients were defined as having RH [24]. However, these numbers overrate the prevalence of $\mathrm{RH}$ as they are performed with older or high-risk patients. In our study we have obtained the frequency of RH similar to other studies $(15.8 \%)$.

Unfortunately, the exact prevalence of RH will most likely remain to be unknown, since it is not quite possible to perform a prospective study with appropriate drug titrations in the general hypertensive population.

The reasons for a poor response are numerous: poor adherence to the therapeutic regimens, potential drug interactions, high salt or alcohol intake, the use of banned drugs, volume overload, sleep apnoea, and obesity. Except for these known factors, we thought that there may be other factors that affect resistance to treatment of hypertension and we evaluated the patients for the duration of hypertension, gender, educational status, and smoking habit. We expected better BP control in the patients with a higher level of education or poor BP control in smokers but the results did not support it.

We report a significant correlation between BMI and resistance to hypertension treatment $(\mathrm{p}=0.005)$. Furthermore, the rate of obese and morbidly obese patients was higher in the RH group $(p<0.005)$. Weight gain increases the incidence of hypertension. The effect of weight gain was shown in a study of more than 80,000 women participating in the Nurse' Health Study [25]. Those women who had gained as little as $5 \mathrm{~kg}$ over their weight at age 18 had a $60 \%$ higher relative risk of developing hypertension than did those whose weight had not changed more than $2 \mathrm{~kg}$; moreover gaining $10 \mathrm{~kg}$ or more, caused a 2.2-fold greater risk. In a cross-sectional study, adults with a BMI $>40$ had 6.38 times greater odds ratio for hypertension [26]. Data from NHANES III shows that the prevalence of high BP augments gradually with increased levels of BMI in men and women; additionally, a progressive increase in the prevalence of hypertension was 
determined with elevated BMI values at all ages [27].

We also report a significant correlation between the duration of hypertension and resistance to hypertension treatment. Duration of hypertension was longer in the $\mathrm{RH}$ group $-9.7 \pm 5.6$ vs $7.0 \pm 5.7$ years $(p<0.001)$. The patients with a longer duration of hypertension had more difficulty to respond to medical treatment.

The need for higher dosage and more medications with the elongation of the duration of hypertension is a common observation. Many questions arise about this. In fact, antihypertensive drugs are limited in terms of variation. Could the continuous effect of the same medication molecules on the same receptors cause a change ('abrasion') in the receptor after a while? Could the non-response to the treatment be owing to the ineffectiveness caused by duration? Is a good BP control sufficient reason not to change the treatment? Would a change in medication from time to time be thought just to overcome 'abrasion'? Even though it is not a strong antihypertensive drug (but a different molecule), the benefit of adding spironolactone in reducing BP supports this thought. The close association of the aldosterone status with $\mathrm{RH}$ resulted in a basis for the proposal of adding low-dose spironolactone as the first step in reducing $\mathrm{BP}$ in patients with $\mathrm{RH}[28,29]$. Low-dose spironolactone $(12.5 \mathrm{mg} / \mathrm{d}$ with the up-titration to $50 \mathrm{mg} / \mathrm{d}$, if required) should be well thought-out in all patients with BP remaining beyond the preferred levels even though treatments with three drugs [30].

Improvements in perception of the pathophysiology of hypertension may allocate the advance of new therapies for RH.

The present study has several limitations. In the follow-ups of patients, we have preferred daily BP measuring at home, instead of periodically measuring BP in the office. Since all the patients had already been diagnosed with hypertension before and, most of them possessed a BP measuring device and a small percentage of the patients acquired a measuring device via friends and relatives, affected our decisions accordingly. Moreover, either themselves or other persons at home, all the patients had experience in measuring BP. We checked the devices that were brought to us, but we cannot claim that all the devices were checked. Even though some setbacks occurred in daily measurements and making notes of BP measurements; the patients made a satisfactory effort in this regard. The fact that the study was done in a metropolis like Istanbul, with understandable reasons, made it difficult for the patients to come for regular follow-ups. Therefore, the planned 24-week patient follow-up process was extended to 36 weeks.

\section{Conclusions}

The mainstay of the treatment of $\mathrm{RH}$ is the removal of exogenous factors and the use of the maximum tolerated doses of combined antihypertensive agents. To attain and maintain goal BP, using multipl drugs, changes in medications and more aggressive strategies should not be avoided. With increasing BMI, BP control gets difficult and increases resistance to treatment. If the duration of hypertension gets longer, it increases the risk of resistance to treatment. In this respect, the duration of hypertension should be considered one of the risks for RH.

\section{References}

[1] Kearney PM, Whelton M, Reynolds K, Muntner P, Whelton $\mathrm{PK}$ et al. Global burden of hypertension: analysis of worldwide data. Lancet 2005; 365 (9455): 217-223. doi: 10.1016/S0140-6736(05)17741-1.

[2] Ong KI, Cheung BM, Man YB, Lau CP, and Lam KSL. Prevalance, awareness, treatment, and control of hipertension among United States adults 1999-2004. Hypertension 2007 Jan; 49 (1): 69-75. doi: 10.1161/01.HYP.0000252676.46043.18.

[3] Wang YR, Alexander GC, Stafford RS. Outpatient hypertension treatment, treatment intensification, and control in Western Europe and the United States. Arch Intern Med. 2007 Jan 22; 167 (2): 141-7. doi: 10.1001/archinte.167.2.141.

[4] Marma AK, Lloyd-Jones DM. Systematic examination of the updated Framingham heart study general cardiovascular risk profile. Circulation 2009; 120 (5): 384-390. doi: 10.1161/circulationaha.108.835470.

[5] Shattuck Lecture. The hypertension paradox-more uncontrolled disease despite improved therapy. N Engl J Med 2009; 361 (9): 878-887. doi: 10.1056/NEJMsa0903829.

[6] Lloyd-Jones DM, Evans JC, Levy D. Hypertension in adults across the age spectrum: current outcomes and control in the community. JAMA 2005; 294 (4): 466-472. doi: 10.1001/jama.294.4.466.

[7] Lewington S, Clarke R, Qizilbash N, Peto R, Collins R et al. Age-specific relevance of usual blood pressure to vascular mortality: a meta-analysis of individual data for one million adults in 61 prospective studies. Lancet 2002; 360 (9349): 1903-1913. doi: 10.1016/S0140-6736(02)11911-8.

[8] Mancia G, Fagard R, Narkiewicz K, Redon J, Zanchetti A et al. $2013 \mathrm{ESH} / \mathrm{ESC}$ guidelines fort the management of arterial hypertension: the Task Force for the Management of Arterial Hypertension of the European Society of Hypertension (ESH) and of the European Society of Cardiology (ESC). Eur Heart J. 2013; 34 (28): 2159-2219. doi: 10.1093/eurheartj/eht151.

[9] James PA, Oparil S, Carter BL, Cushman WC, DennisonHimmelfarb C et al. 2014 evidence-based guideline fort he management of high blood pressure in adults: report from the panel members appointed to the Eighth Joint National Committee (JNC 8). JAMA 2014 Feb 5; 311 (5): 507-20. doi: 10.1001/jama.2013.284427.

[10] American Diabetes Association. Standards of medical care in diabetes-2013. Diabetes care 2013 Jan; 36 (suppl 1): S11-S66. doi.org/10.2337/dc13-S011.

[11] Kidney Disease; Improving Global Outcomes (KDIGO) Blood Pressure Work Group. KDIGO clinical practice guideline for the management of blood pressure in chronic kidney disease. Kidney Int Suppl. 2012; 2 (5): 337-414.

[12] Hajjar I, Kotchen TA. Trends in prevalence, awareness, treatment, and control of hypertension in the United States, 1988-2000. JAMA. 2003 Jul 9; 290 (2): 199-206. doi: 10.1001/jama.290.2.199. 
[13] Lloyd-Jones DM, Evans JC, Larson MG, O’Donnell CJ, Rocella EJ et al. Differential control of systolic and diastolic blood pressure: factors associated with lack of blood pressure control in the community. Hypertension. 2000; 36 (4): 594-9. doi: 10.1161/01.hyp.36.4.594.

[14] Peralta CA, Hicks LS, Chertow GM, Ayanian JZ, Vittinghoff $\mathrm{E}$ et al. Control of hypertension in adults with chronic kidney disease in the United States. Hypertension. 2005 Jun; 45 (6): 1119-24. doi: 10.1161/01.HYP.0000164577.81087.70.

[15] The ALLHAT Officers and Coordinators for the ALLHAT Collaborative Research Group. Outcomes in high risk hypertensive patients randomized toangiotensinconvertingenzyme inhibitor or calcium channel blocker vs diuretic: The Antihypertensive and Lipid-Lowering Treatment to prevent Heart Attack Trial (ALLHAT). JAMA. 2002 Dec 18; 288 (23): 2981-97. doi: 10.1001/jama.288.23.2981.

[16] Julius S, Kjeldsen SE, Weber M, Brunner HR, Ekman S et al. Outcomes in hypertensive patients at high cardiovascular risk treated with regimens based on valsartan or amlodipine: the VALUE randomised trial. Lancet. 2004 Jun 19; 363 (9426): 2022-31. doi: 10.1016/S0140-6736(04)16451-9.

[17] Dahlöf B, Sever PS, Poulter NR, Wedel H, Beevers DG, Caulfield M, et al. Prevention of cardiovascular events with an antihypertensive regimen of amlodipine adding perindopril as required versus atenolol adding bendroflumethiazide as required, in the Anglo-Scandinavian Cardiac Outcomes TrialBlood Pressure Lowering Arm (ASCOT-BPLA): a multicentre randomised controlled trial. Lancet. 2005 Sep 10; 366 (9489): 895-906. doi: 10.1016/S0140-6736(05)67185-1.

[18] Black HR, Elliott WJ, Grandits G, Grambsch P, Lucente T et al. Principal results of the Controlled Onset Verapamil Investigation of Cardiovascular End Points (CONVINCE) trial. JAMA. 2003 Apr 23-30; 289 (16): 2073-2082. doi: 10.1001/jama.289.16.2073.

[19] Swales JD, Bing RF, Heagerty A, Pohl JE, Russell GI et al. Treatment of refractory hypertension. Lancet 1982: 319 (8277): 894-896. doi.org/10.1016/S0140-6736(82)92162-6
[20] Frohlich ED. Classification of resistan hypertension. Hypertension. 1988 Mar; 11 (3 Pt 2): 1167-70. doi: 10.1161/01.hyp.11.3_pt_2.ii67.

[21] 1988 Joint National Committee. The 1988 report of the Joint National Committee on Prevention, Detection, Evaluation, and Treatment of High Blood Pressre. Arch Intern Med 1988; 148 (5): 1023-1038.

[22] Alderman MH, Budner N, Cohen H, Lamport B, Ooi WL. Prevalance of drug resistant hypertension. Hypertension 1988; 11: (Suppl II): 1171-1175.

[23] Staessen JA, Fagard R, Thijs L, Celis H, Arabidze GG, Birkenhager WH, et al. Randomised double-blind comparison of placebo and active treatment for older patients with isolated systolic hypertension. Lancet 1999; 350: 757-764.

[24] Kjedsen SE, Dahlöf B, Devereux R, Julius S, Beevers G, Faire $\mathrm{U}$, et al. For the LIFE study group. One year of antihypertensive treatment in patients with LVH: the LIFE study. Am J Hypertens 1999; 12: 142.

[25] Huang Z, Willett WC, Manson JE, Rosner B, Stampfer MJ, Speizer FE, et al. Body weight, weight change, and risk of hypertension in women. Ann Intern Med 1998; 128: 81-88.

[26] Mokdad AH, Ford ES, Bowman BA, Dietz WH, Vinicor F, Bales VS, et al. Prevalance of obesity, diabetes and obesityrelated health risk factors, 2001. JAMA 2003; 289: 76-79.

[27] Thompson D, Edelsberg J, Colditz GA, Bird AP, Oster G. Lifetime health and economic consequence of obesity. Arch Intern Med 1999; 159: 2177-2183.

[28] Chapman N, Dobson J, Wilson S, Dahlöf B, Sever PS, Wedel $\mathrm{H}$, et al. Effect of spironolactone on blood pressure in subjects with resistant hypertension. Hypertension 2002; 39: 982-988.

[29] Nishizaka MK, Zaman MA, Calhoun DA. Efficacy of lowdose spironolactone in subjects with resistant hipertansion. Am J Hypetens 2003; 16: 925-930.

[30] Primenta E, Calhoun DA. Treatment of resistant hypertansion. J Hypertens 2010; 28: 219-2195. 